\title{
APPLiCATION OF THE QUALITY FUNCTION DEPLOYMENT APPROACH TO THE OPTIMIZATION OF AN ENTERPRISE Resource Planning SOFtWARE
}

\author{
Samuele Marinello ${ }^{1 *}$, Sonia Bertè ${ }^{2}$, Francesco Lolli ${ }^{1,2} \&$ Maria Angela Butturi ${ }^{2}$ \\ University of Modena and Reggio Emilia, Via Amendola 2, Padiglione Morselli, 42122 Reggio Emilia, Italy
}
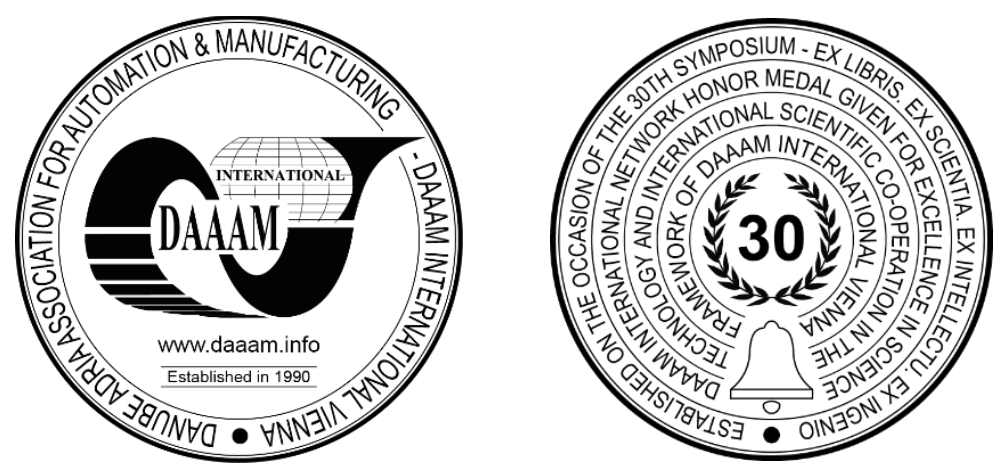

This Publication has to be referred as: Samuele, M[arinello]; Berte, S[onia]; Lolli, F[rancesco] \& Butturi, M[aria] A[ngela] (2020). Application of the Quality Function Deployment Approach to the Optimization of an Enterprise Resource Planning software, Proceedings of the 31st DAAAM International Symposium, pp.0926-0935, B. Katalinic (Ed.), Published by DAAAM International, ISBN 978-3-902734-29-7, ISSN 1726-9679, Vienna, Austria DOI: $10.2507 / 31$ st.daaam.proceedings. 129

\begin{abstract}
Enterprise Resource Planning (ERP) software are essential tools for those business activities that want to be competitive on the market: their use allows to manage all the economic and organizational aspects of a company, optimizing the use of resources. For this reason, the structure and functions of this software must be able to manage countless heterogeneous business aspects and, often, characteristic for each individual company. Therefore, during the design and the development phases it is necessary to analyze and understand the interests and needs of the end users, combining them with technical and market aspects. An approach capable of combining these aspects is the House of Quality (HoQ), a tool of Quality Function Deployment. It, applicable to new products or to the optimization of existing ones, allows to effectively identify and order the technical specifications and functions of the software (HOWs) by evaluating the most important requests of user customers (WHATs). This study describes the application of HoQ to the optimization of an ERP software, identifying the main critical elements in the existing configuration and co-designing a new version through the direct involvement of users, evaluating the importance of their needs.
\end{abstract}

Keywords: Enterprise Resource Planning software; Optimization; Product co-design; Quality Function Deployment; House of Quality

\section{Introduction}

Today, Enterprise Resource Planning (ERP) software represents a resource of absolute importance for company management in order to grow their business. Through an ERP software it is possible to control, manage and optimize the functioning of each organization that uses it, favoring a significant competitive advantage on reference market [1], [2]. ERP solutions exploit technology to improve the efficiency of management, design, production planning and aggregation of data flows in order to have a continuous "chain" from the production of goods or supply of services, up to the final consumer [3], also favored by the diffusion of the typical solutions of Industry 4.0 [4]. 
In addition to the operational advantages, the widespread diffusion of these software is favored by a market in which the Information Technology (IT) sector is constantly growing and promotes the transition of production activities towards digital innovation [5]. If we analyze the current market trends, it is evident that ERP software is considered as the main tool for successfully managing companies from a digital transformation perspective: these systems, in fact, constitute the database where are allocated all company data [3] and, moreover, they must be able to be suitable tools for software users to predict and plan in the best possible way the economic and business results [6].

In order to obtain similar advantages and benefits from their use, a large-scale diffusion of this type of software has taken place, among multinationals and among small and medium-sized enterprises [7]. In particular, in order to meet in a better way the needs of the particular business of small and medium-sized enterprises, the implementation of ERP software is integrated with customizations [8], [9]. Through the combination of efficiency and effectiveness, it is possible to ensure better management of resources, increase profitability, support decion making, planning and improving business performance [10]. The effect of the implementation of ERP software brings significant advantages: as reported by [11], their use promote an average reduction in costs for raw materials and production resources of about $17 \%$, production costs of $19 \%$, an overall cost reduction by $9 \%$, inventory volume optimization by $26 \%$, order execution time reduction by $24 \%$, labor costs reduction by $29 \%$ and an increase average profits of $9 \%$. The main difficulty encountered in the implementation of ERP software in a business environment is the high initial investment in terms of time and money: this is why the focus is on customer satisfaction through the quality of the software [12]. In fact, it is not possible to create successful software products that do not include those functions and characteristics necessary to fulfill the requests of the end customer. ERPs are constantly driven by customers' needs and expectations [13]. In order to create and keep up-todate a product that is always in step with market needs, it is useful to involve the customer in the development process [14], [15], [16] from a practical perspective of co-design. The approach adopted in this study consists in the application of Quality Function Deployment (QFD) and its quality houses. QFD is recognized worldwide as a powerful decision support tool in product and service innovation contexts, capable of maximizing overall customer satisfaction [17], [18], [19]. It is a methodology used to convert customer needs into measurable characteristics and indicators of the various processes, components and activities necessary for the realization of the product. QFD can be defined as "a system to make sure that customer needs guide the product design and manufacturing process" [20], [21]. It is used to transfer customer needs into business processes: from design to production [22]. The QFD ultimately helps managers or members of a work team make operational decisions and make the necessary compromises by providing a comprehensive, clear and robust methodological path. The QFD development process involves the construction of four "houses" [23], [24]: each of these will be represented by a table, which will have inputs (WHATs) and outputs (HOWs). In particular, the outputs of the previous house will be the inputs of the next house.

The aim of this work is to describe the use of the HoQ tool for the development and optimization of an ERP software created by an Italian company. In particular, this study defines the operational approach adopted and the methods of normalization and prioritization of the technical functions that represent the SW.

\section{Some bibliographic evidence}

The QFD approach is widely disseminated in the literature, thanks to its multidisciplinary approach to the analysis of the characteristics of a product or service and as a driving force in customer engagement and involvement in the cocreation of value. This has been addressed in several studies, such as [25], [26], [27], [28]. As described by [14], [15], [16], the customer is a crucial element in the entire design and development phase of products and services intended for him. This promote innovation processes and determines the key to success on the market [29], [30].

Applied to the aspect of digital technologies to support business activities, such as software and IT platforms, the QFD is widely disseminated. In the field of e-commerce [31] and [32] apply the HoQ to identify the ways of structuring ecommerce platforms through the involvement of customers. [23] study the methods of designing a system of manufacturing platforms for unassembled products with the HoQ tool. [33] uses it to design the structure of a mobile telephone, with access and navigation to digital content. [34] and [35] apply this approach to establish the priority improvements to the software engineering process, applying a framework-QFD CMMI continuous representation. [36] apply two quantitative approaches for setting target values. [37] adopt a hybrid framework of Fuzzy Cognitive Network Process, Aggregative Grading Clustering, and Quality Function Deployment (F-CNP-AGC-QFD) for the criteria evaluation and analysis in QFD with an application to cloud software product development.

Specifically to the development of ERP software, QFD tools have been described in the studies of [36] that develop a new decision framework for ERP software selection based on QFD and fuzzy linear regression to enable analysis of impact of unachieved target values on customer satisfaction. [38] proposes a step-based model to select ERP software effectively and efficiently. In particular, the model considers the qualitative characteristics of the software and takes into account three main criteria: the manufacturer, the cost of implementation and the time factor. These criteria have been divided into sub-criteria. Regarding the software, six key qualitative attributes are taken into account: functionality, reliability, usability, efficiency, maintainability, portability. [39] apply the Analytic Hierarchy Process (AHP) and Technique for Order of Preference by Similarity to Ideal Solution (TOPSIS) models combined together as a way to apply the multi-criteria decision-making process for the choice of ERP software as well as in many other areas and business structures. [40] present a model for ERP risk management through the assessment of the most influential ERP risks and the preventive activities to reduce the impacts of these risks. 
In the study of [41] the fuzzy AHP is used to determine the relative importance of the different criteria. The support of top management and a solid financial condition for the company are essential for the choice of ERP software. There are many factors to take into consideration when choosing the implementation of an ERP software, including ease of use, integration and compatibility between old systems and new systems, purchase and maintenance costs. In order to use the AHP method to choose an ERP software, the research described has been based on the construction of a hierarchy among the different ERP software with their respective characteristics. [42] develop a methodological proposal that allows to consider both the company's requests and the characteristics of the ERP system and provides the means to choose the most complete and suitable software for business purposes. [43] apply the Analytic Network Process (ANP) model in decision problems of choice of ERP software. [44] apply the AHP method is applied for dealing with the ambiguities involved in the assessment of ERP alternatives and relative importance weightings of criteria.

\section{Research approach}

In the literature there are numerous approaches used to structure the HoQ and to appropriately combine the three main factors that constitute it: customer needs, technical parameters, market analysis. [45] provided a structured review of the theme, also from a graphic point of view. Further developments are described in numerous papers, mainly focused on data analysis and aggregation approaches, developing models with multi-criterion approaches [46], [47], [48], [49].

In this study, the approach adopted in applying the HoQ is shown in Figure 1.

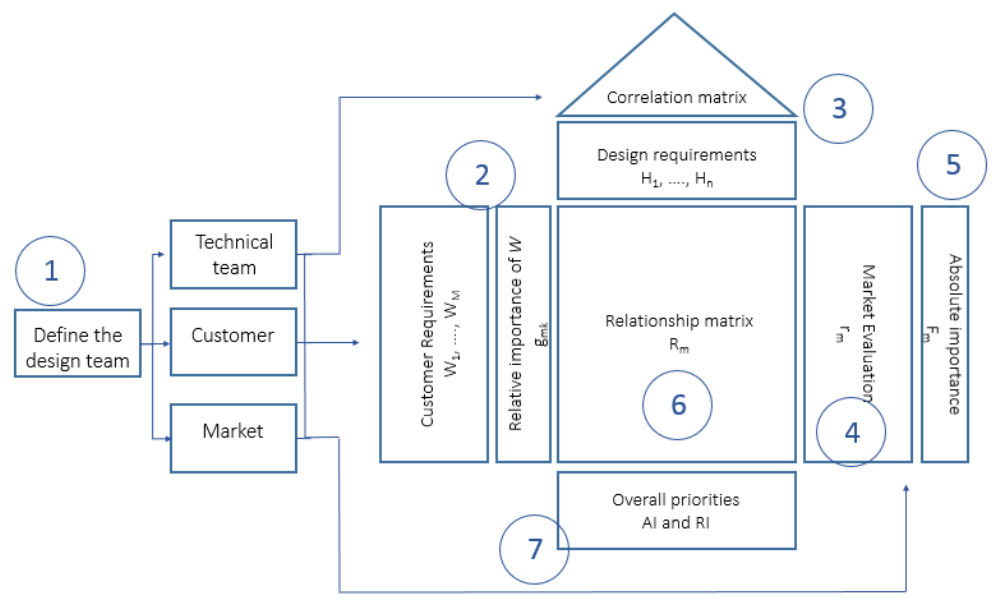

Fig. 1. House of quality with a 7-step model.

1. Project team: a multidisciplinary R\&D group must be developed to properly analyze data and inputs from customers, technical developers and competitor evaluations.

2. Customer needs (WHATs): they are expressed, usually, through a non-technical language and, therefore, difficult to interpret. This is particularly common especially for business to consumer products. In the case of business-to-business, on the other hand, the gap between the language of the customer and that of the supplier is considerably reduced, while maintaining a certain distance. The customers involved in this phase must be representative of the reference market: therefore, segmentation is vital to analyze the customer's voice and to identify their needs. Kano, who introduced the idea of "Attractive Quality", classifying needs into 3 groups: implicit (discounted by the customer and, therefore, not declared), explicit (those that the customer expressly declares) and latent (those of which the client is not yet aware) [50], [51], [52].

Interviews, questionnaires market researchs and focus groups are some of the main techniques used to collect customer needs. Mathematically, we list with $k=1, \ldots K$ the $K$ number of customers and with $m=1, \ldots, M$ the $M$ the number of collected requirements. Each WHAT is indicated with $W_{m}$. If $M$ has a very high value, the structuring of customer needs is necessary through their grouping into meaningful hierarchies or categories [45]. The $K$ customers attribute a $g_{m k}$ score to each $W_{m}$, identifying the subjective importance. The Likert scale [53] is a possible alternative through values between 1 (very unimportant) and 5 (most important). The relative importance is calculated for each need by making the arithmetic mean of the judgments collected (eq. 1). The average $G_{m}$ is therefore used to represent each WHAT.

$$
G_{m}=\sum_{k=1}^{K} \frac{g_{m k}}{K}, m=1, \ldots, M
$$

3. Identify the design requirements $(\mathrm{HOWs})$ : they are the technical-engineering parameters that translate the needs of clients [54]. In practice, these are the concrete answers that the company can offer to customer needs and which directly influence the customer's perception of quality. $N$ is the number of collected HOWs, indexed by $n=1, \ldots, N$.

The matrix, which constitutes the roof of the house, the characteristics are compared one by one. It highlights how the characteristics are related to each other and how changing one behaves (positively or negatively) the others. This area can make it possible to identify opportunities or to highlight contradictions. This evaluation takes place through a symbolic representation. 
4. Competitors and customer competitive assessment: the main competitors in the relevant markets must be identified. The comparison with competitors allows to evaluate the distance of the product concerned with respect to the characteristics of competing products. The assessment of the gap is entrusted to customers on the identified WHATs, usually expressed and measured on the same scale of step 2.

Indicating with $C_{l}$ a competitor among the $L$ competitors used as benchmark, with $l=1, \ldots \mathrm{L}$, the evaluation result are $\mathrm{K}$ matrixes $\mathrm{X}_{\mathrm{k}}$ of dimension $(\mathrm{MxL})$, one for each $\mathrm{k}=1, \ldots, \mathrm{K}$, reporting the WHATs and the competitors in rows and colums, respectively (eq. 2). Each score into the said matrix is indicated with $\mathrm{g}_{\mathrm{mlk}}$, with $\mathrm{m}=1, \ldots, \mathrm{M}$ and $\mathrm{l}=1, \ldots \mathrm{L}$. Thereby, the competitive gap $r_{m}$ (eq. 3) can be evaluated for each $W_{m}$ as the ratio between the highest score reached by the best competitor on $W_{m}$ and the score $G_{m}$ achieved in step 2 (see eq. 1), with $m=1, \ldots M$. The higher the $r_{m}$ value, the greater the commitment that the company will have to place on that particular $\mathrm{W}_{\mathrm{m}}$.

$$
\begin{aligned}
& X_{k}=\left[\begin{array}{ccc}
g_{11 k} & \cdots & g_{1 L k} \\
\vdots & \ddots & \vdots \\
g_{m 1 k} & \cdots & g_{M L k}
\end{array}\right]_{M x L} \text { with } k=1, \ldots K \\
& r_{m}=\frac{G_{m}}{\max _{k=1, \ldots, K}\left\{l \max _{l=1, \ldots, L}\left\{g_{m l k}\right\}\right.} \text { with } m=1, \ldots M \\
& F_{m}=G_{m} \cdot r_{m} \text { with } m=1, \ldots M \\
& A I_{n}=\sum_{m=1}^{M} F_{m} \cdot c_{m n} \text { with } n=1, \ldots N \\
& R I_{n}=\frac{A I_{n}}{\sum_{n=1}^{N} A I_{n}} x 100 \text { with } n=1, \ldots N
\end{aligned}
$$

5. Absolute importance assessment: this is the combination between the score assigned to each WHAT $\left(G_{m}\right)$ and the competitive gap $\left(r_{m}\right)$ that determine the absolute score Fm for each WHAT (eq. 4).

$$
F_{m}=G_{m} \cdot r_{m} \text { with } m=1, \ldots M
$$

6. Relationship needs/characteristics matrix: the relationships between each elementary need and each product characteristic are established, also establishing the intensity of this relationship usually with the values 1 (low correlation), 5 (normal correlation) and 9 (strong correlation) [45,55]. This value is referred to as $\mathrm{c}_{\mathrm{mn}}$.

7. Importance of the characteristics: the most relevant/critical characteristics are highlighted, which will guide the development of the project. The absolute index $\left(A I_{n}\right)$ or their relative index $\left(R I_{n}\right)$, with $n=1, \ldots N$ are calculated to normalize and sort the HOWs (eq. 5 and 6).

$$
\begin{aligned}
& A I_{n}=\sum_{m=1}^{M} F_{m} \cdot c_{m n} \text { with } n=1, \ldots N \\
& R I_{n}=\frac{A I_{n}}{\sum_{n=1}^{N} A I_{n}} x 100 \text { with } n=1, \ldots N
\end{aligned}
$$

\section{Case study}

The HoQ has been applied through a practical case represented by the need to optimize an Enterprise Resource Planning (ERP) software developed and marketed by an Italian company. The company operates as a system integrator for customers operating in very different economic sectors, supporting the integration of new software and hardware solutions within the business process. The results of the study are functional to the company's need to become more competitive, retain its customers and expand its market share. The results of the case study are described with respect to each phase of the development of the HoQ, as described in section 3. The project team has been coordinated by the software developer, involving its technical and commercial/marketing departments. The university has been involved with the scientific support role. Numerous customers have been also involved, including new prospects. $W_{m}$ WHATs and $g_{m k}$ scores have been identified and quantified using two approaches: personal interview and market research. This allowed to obtain representative information of $\mathrm{K}=50$ number of customers and $\mathrm{M}=36$ number of collected requirements. Table 1 shows the list of WHATs and the importance assigned. Since an ERP software operates at the service of numerous company functions, the WHATs have also been grouped according to the function most involved and represented by each WHAT. The identified WHATs made it possible to collect and synthesize customer expectations with respect to an ERP software. The scores assigned highlighted the needs that have a higher value. Overall, the "5" value is the most frequent among the WHATs, occurring in 58\% of cases. The "2" score represents $30 \%$ of the WHATs, followed by the " 3 " and " 1 " scores with a frequency of $6 \%$ each. The score " 4 " was never assigned.

The results highlight a particular relevance towards the aspect of production where the maximum score (corresponding to 5 on the Likert scale used in this study) has been found in $77 \%$ of WHATs. On the contrary, "Warehouse and Logistics" 
are the least relevant aspects, with only $27 \%$ of WHATs having the maximum score. In this case, the score "2" is the most frequent (54\%). This is the only company function with WHATs considered "very unimportant" by customers: they are represented by the "W26. order fulfillment and delivery plans updated in real time" and from "W36. possibility of making multi-order withdrawals".

\begin{tabular}{|c|c|c|c|c|c|c|c|}
\hline \multirow{2}{*}{$\begin{array}{l}\text { Business } \\
\text { function }\end{array}$} & \multirow{2}{*}{ WHATs } & \multicolumn{5}{|c|}{$\mathrm{GM}_{\mathrm{M}}$} & \multirow{2}{*}{$\begin{array}{c}\text { Relative } \\
\text { importance }\end{array}$} \\
\hline & & 1 & 2 & 3 & 4 & 5 & \\
\hline \multirow{10}{*}{ Sales } & $\begin{array}{l}\text { W1. Availability of control systems that detect the deviation of } \\
\text { the margin from the target for each order }\end{array}$ & & 2 & & & & 0.015 \\
\hline & W2. Comparison with budgets measured on margins & & 2 & & & & 0.015 \\
\hline & W3. Tools to quickly access all information on customers & & & & & 5 & 0.037 \\
\hline & $\begin{array}{l}\text { W4. Need to manage the network of relationships with partners } \\
\text { to expand their market share }\end{array}$ & & & & & 5 & 0.037 \\
\hline & W5. Need to observe the regulatory aspects of the company & & & & & 5 & 0.037 \\
\hline & W6. Need to easily obtain sales statistics & & 2 & & & & 0.015 \\
\hline & W7. Need for sales incentive tools & & & & & 5 & 0.037 \\
\hline & W8. Multilingual support, to produce documents for abroad & & & & & 5 & 0.037 \\
\hline & W9. Adaptation of the tool to use habits & & & & & 5 & 0.037 \\
\hline & W10. Adaptation of the tool to the customer's processes & & & & & 5 & 0.037 \\
\hline \multirow{6}{*}{ Purchase } & $\begin{array}{l}\text { W11. Intemational sourcing, selection of strategic suppliers and } \\
\text { the most convenient contractual agreements }\end{array}$ & & & & & 5 & 0.037 \\
\hline & $\begin{array}{l}\text { W12. Management of purchases and new contacts with suppliers } \\
\text { via internet }\end{array}$ & & & 3 & & & 0.022 \\
\hline & $\begin{array}{l}\text { W13. Research and selection of new suppliers, brands, products } \\
\text { and services to be included in the assortment }\end{array}$ & & 2 & & & & 0.015 \\
\hline & $\begin{array}{l}\text { W14. For risk management: analysis of suppliers' financial } \\
\text { difficulties, price volatility, possible supply internuptions }\end{array}$ & & & & & 5 & 0.037 \\
\hline & $\begin{array}{l}\text { W15. Use of CLOUD technologies to speed up IT } \\
\text { implementation and reduce costs }\end{array}$ & & & & & 5 & 0.037 \\
\hline & $\begin{array}{l}\text { W16. Strategic decision support by exploiting the information } \\
\text { available in the company }\end{array}$ & & & & & 5 & 0.037 \\
\hline \multirow{9}{*}{ Production } & W17. Availability of tools for determining product costs & & & & & 5 & 0.037 \\
\hline & $\begin{array}{l}\text { W18. Malke-to-individual approach: extreme product } \\
\text { customization based on the order }\end{array}$ & & & & & 5 & 0.037 \\
\hline & W19. Access to management data from anywhere & & & & & 5 & 0.037 \\
\hline & $\begin{array}{l}\text { W20. Acquisition of production data, with movement detected } \\
\text { both by the operator and automatically }\end{array}$ & & & & & 5 & 0.037 \\
\hline & $\begin{array}{l}\text { W21. MPS functionality: tool that fixes the quantities to be } \\
\text { produced and the times }\end{array}$ & & & & & 5 & 0.037 \\
\hline & $\begin{array}{l}\text { W22. Lean manufacturing: production is driven by sales, so that } \\
\text { only what has been sold or will soon be produced }\end{array}$ & & & & & 5 & 0.037 \\
\hline & $\begin{array}{l}\text { W23. Lightening of stocks of raw materials and semi-finished } \\
\text { products, with reduction of warehouse management costs }\end{array}$ & & & & & 5 & 0.037 \\
\hline & W24. Optimization of the production process phases & & 2 & & & & 0.015 \\
\hline & W25. Reduction of waste and production excesses & & & 3 & & & 0.022 \\
\hline \multirow{11}{*}{$\begin{array}{l}\text { Warehouse } \\
\text { and } \\
\text { Logistics }\end{array}$} & W26. Order fulfillment and delivery plans updated & 1 & & & & & 0.007 \\
\hline & $\begin{array}{l}\text { W27. Strict control over the timing of each order and the stock } \\
\text { entities aniving or to be ordered (MRP) }\end{array}$ & & 2 & & & & 0.015 \\
\hline & $\begin{array}{l}\text { W28. Support for managing the coding of articles and variants } \\
\text { within extensive catalogs }\end{array}$ & & 2 & & & & 0.015 \\
\hline & W29. Incoming logistics management & & & & & 5 & 0.037 \\
\hline & W30. Intemal logistics management & & & & & 5 & 0.037 \\
\hline & W31. Outbound logistics & & & & & 5 & 0.037 \\
\hline & W32. Accurate inventory labeling and mapping & & 2 & & & & 0.015 \\
\hline & W33. Use of barcode labels & & 2 & & & & 0.015 \\
\hline & $\begin{array}{l}\text { W34. Use of barcode scanners and a warehouse management } \\
\text { system (WMS) }\end{array}$ & & 2 & & & & 0.015 \\
\hline & W35. Reorganization of loading units to optimize volumes & & 2 & & & & 0.015 \\
\hline & W36. Possibility to make multi-order withdrawals & 1 & & & & & 0.007 \\
\hline
\end{tabular}

Table 1. WHATs list and relative importance.

The list of HOWs in this specific case, highlights different and diversified aspects. In this study the most relevant and representative ones have been considered, selected through analyzes that involved ERP consultants and company project managers in the foreground. Overall, $\mathrm{N}=12$ numbers of HOWs have been selected, as shown below:

- H1. Configuration and setting of parameters and tables.

- H2. Full implementation of third party packages.

- H3. Screen masks for data input and output, to optimize the use of information.

- H4. Workflow scheduling.

- H5. Standard storage system interface.

- H6. Development of statistical functions for particular metrics.

- H7. ERP programming of additional applications, without changing the source code.

- H8. Interface with the custom shop system or with a Customer Relationship Management (CRM) package.

- H9. Modification of source codes with small modifications to change entire modules. 
- H10. Error notification resulting in a change in production planning.

- H11. Frequent software updates.

- H12. Personalized reporting.

With the determination of the technical characteristics, it is possible to complete the roof of the HoQ. The matrix that makes up the roof of the HoQ relates the different characteristics, which can have a positive, negative or zero correlation. In this specific case, represented in Figure 2, to identify the correlation between the HOWs, an objective analysis has been carried out to understand if the technical characteristics could somehow meet the same needs, and if so, to what extent.

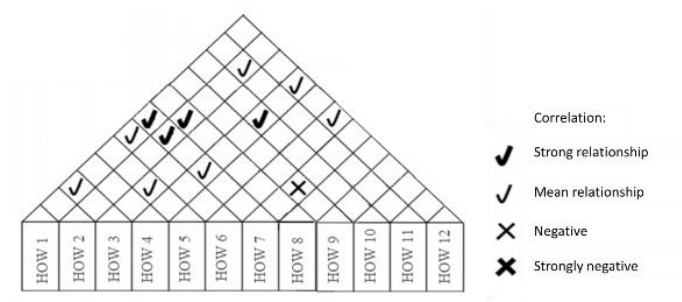

Fig. 2. HOWs correlation matrix.

The analysis made it possible to identify the following conditions: four strong relationships involving HOWs n. 1, 2, 4, 7, 8, 10; 7 mean relationships and one negative relationship. The two HOWs are in conflict as it is possible to decide whether to modify the source codes or not. The comparative analysis between the ERP software of the main competing companies, both national and international, has been conducted, through the involvement of the company's commercial and maketing department, as well as with the direct involvement of customers who have already supported the WHATs identification phase. In particular, L = 5 main competitor ERP software have been identified, developed by as many companies operating in different parts of the world. The $\mathrm{K}=50$ number of customers were asked to provide an evaluation for each WHAT with respect to each ERP software. Table 2 report the results of the competitive analysis.

The comparison with competitors allows to evaluate the gap and, consequently, to identify the software functions to be implemented with greater effort. The $r_{m}$ index provides an immediate indication about this aspect: if the index value is less than 1 it means that our software is superior to the best competitor. If the value of $r_{m}$ is greater than 1 , the condition is contrary. Finally, if the index is equal to 1 , the products are equivalent.

Overall, these three conditions occur quite homogeneously: about $39 \%$ of values higher than $1,33 \%$ equal to 1 and $28 \%$ lower than 1. "W20. acquisition of production data, with movement detected both by the operator and automatically" is the aspect of the ERP software being analyzed that most positively distinguishes it from the competition (it has an $r_{m}$ index value of 0.4). The most critical elements (because they have a much lower level than the other software compared) are "W26. order fulfillment and delivery schedules updated in real time" and "W36. possibility of making multi-order withdrawals". By analyzing the results of the gap analysis with respect to company functions, production is the one that concentrates more functions better than the other competitors. Sales are those that have performances considered similar to competitors, while the warehouse and logistics are those that most frequently have worse performances.

The calculation of absolute importance further strengthens these considerations. Analyzing for example the W20, it received the highest score from customers and was already a much higher factor than all the competition. The $F_{m}$ index, which is precisely the combination of these two aspects (importance and gap), has the lowest score among all WHATs. Therefore, although it is very important from a relative point of view, it is not so in an absolute sense.

These obtained results are combined with each other through the relationship matrix and through the quantification of the relationship values between WHATs and HOWs, as reported in Table 3. The relationship matrix made it possible to identify and quantitatively evaluate the relationship between WHATs and HOWs. Weak relationships are the most frequent case, detected 64 times. 31 cases express strong relationship and 19 express a mean relationship. In 318 times there is no relationship. The results highlight the following aspects:

- H4 represents the HOW connected with a high number of WHATs (overall 24), although in many cases there is a weak relationship (14 times). A strong relationship is detected 6 times.

- H9 is the HOW with less relationship with the WHATs. Only 2 weak relationships have been identified.

- W6 and W15 have more links than the HOWs: 8 each, well balanced between the three value classes used.

- There are many WHATs that have only one link with HOWs. Overall, 8 WHATs belong to this series.

Table 3 reports also the combination of the values assigned to each relationship and the previously determined $F_{m}$ value (Table 2). This index is important because allows the combination of all three main elements that support the codesign of the software structure: customer needs, product technical characteristics and competitive benchmarking.

The values obtained vary between a minimum of 2 (present once in relation to WHAT n.20 with HOW n.5) and a maximum of 45 (present 20 times, especially in correspondence with HOW n.12 and WHAT n.15). The highest values indicate situations in which there is a high relationship between WHAT and HOW and with high values of $F_{m}$ (which express the combination between the importance of the need and the competitive gap). 


\begin{tabular}{|c|c|c|c|c|c|c|c|c|}
\hline $\begin{array}{l}\text { WHATs } \\
\text { group }\end{array}$ & $\begin{array}{l}\text { Reference } \\
\text { ERP SW }\end{array}$ & $\begin{array}{c}\text { Competitor } \\
\mathrm{Cl}\end{array}$ & $\begin{array}{c}\text { Competitor } \\
C 2\end{array}$ & $\begin{array}{c}\text { Competitor } \\
\text { C3 }\end{array}$ & $\begin{array}{c}\text { Competitor } \\
\mathrm{C} 4\end{array}$ & $\begin{array}{c}\text { Competitor } \\
\text { C5 }\end{array}$ & $r_{m}$ & $F_{m}$ \\
\hline W1 & 2 & 2 & 3 & 5 & 4 & 3 & 2,5 & 5 \\
\hline W2 & 2 & 2 & 2 & 3 & 3 & 3 & 1,5 & 3 \\
\hline W3 & 5 & 4 & 4 & 5 & 5 & 5 & 1,0 & 5 \\
\hline W4 & 5 & 2 & 3 & 5 & 4 & 3 & 1,0 & 5 \\
\hline W5 & 5 & 4 & 2 & 4 & 4 & 4 & 0,8 & 4 \\
\hline W6 & 2 & 2 & 3 & 5 & 4 & 3 & 2,5 & 5 \\
\hline W7 & 5 & 3 & 3 & 5 & 4 & 3 & 1,0 & 5 \\
\hline W8 & 5 & 5 & 5 & 5 & 5 & 5 & 1,0 & 5 \\
\hline W9 & 5 & 3 & 3 & 5 & 4 & 3 & 1,0 & 5 \\
\hline W10 & 5 & 3 & 3 & 5 & 4 & 3 & 1,0 & 5 \\
\hline W11 & 3 & 3 & 3 & 3 & 3 & 3 & 1,0 & 3 \\
\hline W12 & 2 & 2 & 3 & 5 & 4 & 3 & 2,5 & 5 \\
\hline W13 & 5 & 5 & 5 & 4 & 5 & 5 & 1,0 & 5 \\
\hline W14 & 5 & 3 & 2 & 3 & 4 & 3 & 0,8 & 4 \\
\hline W15 & 5 & 4 & 2 & 3 & 5 & 4 & 1,0 & 5 \\
\hline W16 & 5 & 4 & 4 & 2 & 4 & 4 & 0,8 & 4 \\
\hline W17 & 5 & 4 & 5 & 5 & 4 & 2 & 1,0 & 5 \\
\hline W18 & 5 & 3 & 2 & 5 & 4 & 4 & 1,0 & 5 \\
\hline W19 & 5 & 4 & 4 & 5 & 5 & 4 & 1,0 & 5 \\
\hline W20 & 5 & 2 & 2 & 2 & 2 & 2 & 0,4 & 2 \\
\hline W21 & 5 & 3 & 2 & 4 & 4 & 3 & 0,8 & 4 \\
\hline W22 & 5 & 4 & 3 & 4 & 4 & 3 & 0,8 & 4 \\
\hline W23 & 5 & 4 & 3 & 4 & 4 & 3 & 0,8 & 4 \\
\hline W24 & 2 & 2 & 3 & 5 & 4 & 3 & 2,5 & 5 \\
\hline W25 & 3 & 4 & 2 & 2 & 5 & 2 & 1,7 & 5 \\
\hline W26 & 1 & 2 & 2 & 4 & 2 & 2 & 4,0 & 4 \\
\hline W27 & 2 & 2 & 3 & 5 & 4 & 3 & 2,5 & 5 \\
\hline W28 & 2 & 3 & 3 & 4 & 3 & 3 & 2,0 & 4 \\
\hline W29 & 5 & 3 & 2 & 4 & 3 & 3 & 0,8 & 4 \\
\hline W30 & 5 & 2 & 3 & 4 & 4 & 4 & 0,8 & 4 \\
\hline W31 & 5 & 3 & 2 & 3 & 4 & 3 & 0,8 & 4 \\
\hline W32 & 2 & 2 & 3 & 1 & 4 & 2 & 2,0 & 4 \\
\hline W33 & 2 & 2 & 3 & 3 & 4 & 3 & 2,0 & 4 \\
\hline W34 & 2 & 2 & 3 & 5 & 4 & 3 & 2,5 & 5 \\
\hline W35 & 2 & 3 & 2 & 4 & 4 & 3 & 2,0 & 4 \\
\hline W36 & 1 & 3 & 3 & 4 & 2 & 1 & 4,0 & 4 \\
\hline
\end{tabular}

Table 2. Competitive gap analysis.

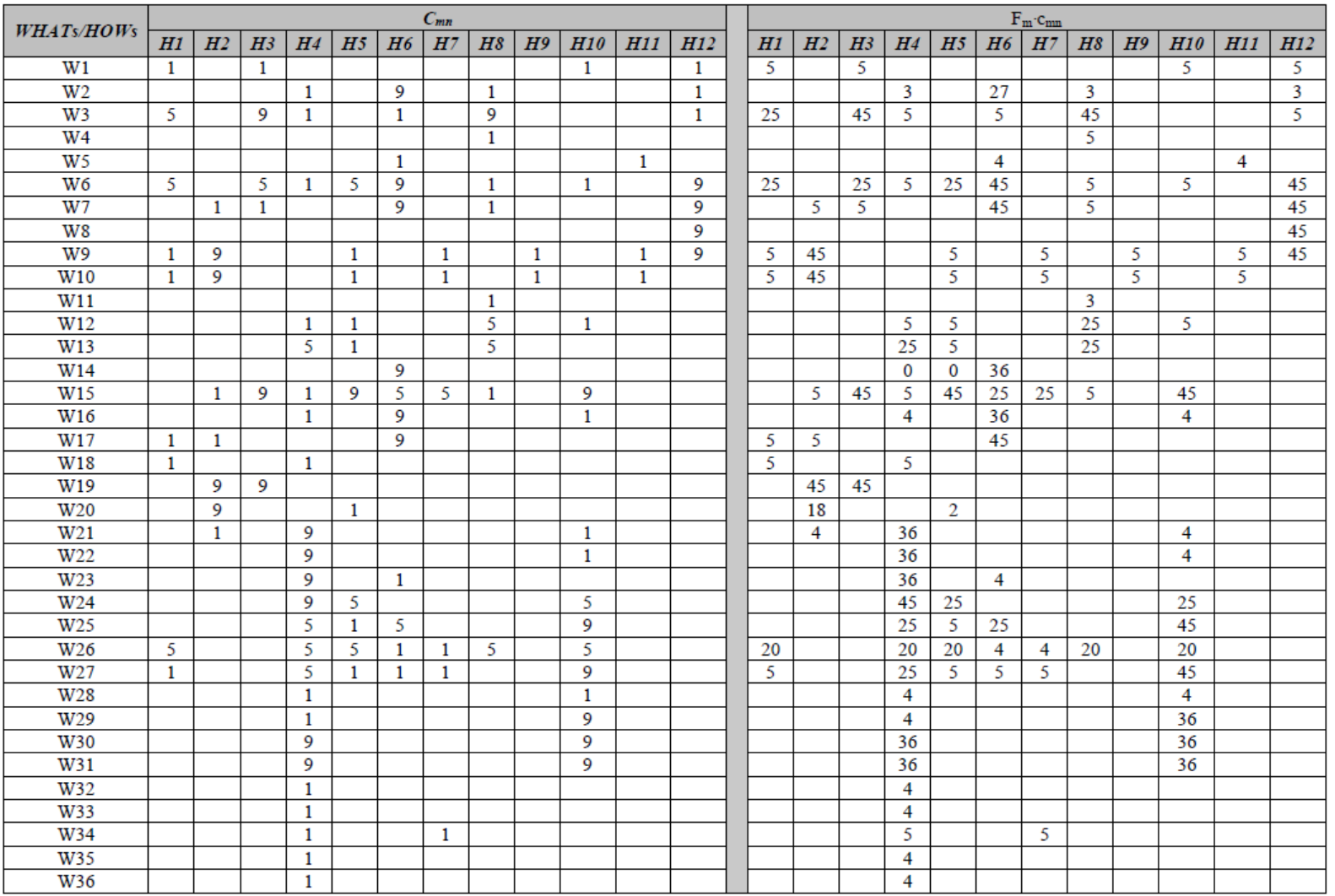

Table 3. Relationship matrix and combination of $\mathrm{F}_{\mathrm{m}}$ and $\mathrm{c}_{\mathrm{mn}}$ values. 
The results of Table 3 allow to complete the final phase of the evaluation through the absolute (AI) and relative (RI) indices of the importance of the technical characteristic. This evaluation allows to order the HOWs with respect to the overall value assumed by each of them. Table 4 reports the results of prioritization through the use of the Independent Scoring Method. In this way, it was possible to identify the technical functionalities that should be the priority object of development, compared to all the others. The results allow the identification of 3 clusters according to the values assumed by the AI index. The first cluster, which includes H4, H6 and H10, is composed of HOWS which have the highest AI values (above 300) and which differ considerably from the values of all the other HOWs (cluster 2 and cluster 3 ). Therefore, these three HOWs are currently the least developed ones (compared to the competition) and with high interest for the customer. The second cluster is made up of WHATs with AI values between 100 and 200. The grouping includes $\mathrm{H} 1, \mathrm{H} 2, \mathrm{H} 3, \mathrm{H} 5, \mathrm{H} 8$ and $\mathrm{H} 12$ and identifies functions that are important, but which require interventions only after having given the necessary attention to those of cluster 1. Finally, the last group includes WHATs with low AI values (in the specific case, less than 50). These features can be optimized last. This is the results obtained through the application of the independent scoring method that is an arbitrary method. Other normalization approaches can be applied. In this study the methods Lyman method [56] and the Wasserman method [57] have been applied. Table 4 shows the results obtained on the rating, using these two methods. The results show a slight change in positions, without however determining a change in the ordering of the HOWs of the first cluster.

\begin{tabular}{|c|c|c|c|c|c|c|c|c|c|c|c|c|}
\hline Importance and rating & Hl & H2 & H3 & H4 & H5 & H6 & H7 & H8 & H9 & H10 & H11 & H12 \\
\hline AI & 101 & 172 & 170 & 381 & 147 & 306 & 49 & 141 & 10 & 319 & 14 & 193 \\
\hline RI & $5 \%$ & $9 \%$ & $8 \%$ & $19 \%$ & $7 \%$ & $15 \%$ & $2 \%$ & $7 \%$ & $0 \%$ & $16 \%$ & $1 \%$ & $10 \%$ \\
\hline Rating & 9 & $\mathbf{5}$ & 6 & 1 & 7 & 3 & 10 & 8 & 12 & $\mathbf{2}$ & 11 & 4 \\
\hline
\end{tabular}

\begin{tabular}{|l|c|c|c|c|c|c|c|c|c|c|c|c|}
\hline Importance and ranking & $\mathrm{Hl}$ & $\mathrm{H} 2$ & $\mathrm{H3}$ & $\mathrm{H} 4$ & $\mathrm{H} 5$ & $\mathrm{H} 6$ & $\mathrm{H} 7$ & $\mathrm{H} 8$ & $\mathrm{H} 9$ & $\mathrm{H} 10$ & $\mathrm{H} 11$ & $\mathrm{H} 12$ \\
\hline Lyman - Rating & 9 & 4 & 6 & 1 & 8 & 3 & 10 & 7 & 11 & $\mathbf{2}$ & 12 & $\mathbf{5}$ \\
\hline Wassermann - Rating & 7 & $\mathbf{5}$ & 4 & 1 & 9 & 3 & 12 & 8 & 10 & $\mathbf{2}$ & 11 & 6 \\
\hline
\end{tabular}

Table 4. Prioritization of HOWs through the application of the independent scoring method (above) and through the application of the Lyman and Wassermann methods

The study conducted, addressing the issue of product optimization through the QFD approach, applies the HoQ to the case study of a commercial ERP software. Although the use of the adopted tool is widely used in the literature, few recent studies have focused on this particular ERP-HoQ binomial. The useful contents provided by this work to the literature concern the collection and description of WHATs and HOWs that can represent relevant aspects for evaluations in the design and development of software solutions (not only of the ERP type), as well as the proposed standardization approaches and discussed through a numerical example.

\section{Conclusions and future developments}

This study tried to analyze how it is possible to provide its customers with a higher quality of the product offered, applied to the case of an ERP software. This question is the basic principle of Total Quality Management, applied by the most successful companies in the world. Ensuring the quality of a good or service is not easy and obvious: it is necessary to identify the needs of customers, both conscious and unconscious, and if possible anticipate them. Then it is necessary to find a way to satisfy them: this corresponds to a compromise between costs, benefits, risks, quality. For these reasons, it becomes necessary to apply a structured study method. It is not enough to study how to optimize one's business processes or carry out market studies with respect to competitors. In this sense, the identification of strengths and weaknesses, studied through the Quality Function Deployment method, is a solid scientific and objective method that allows for both qualitative and quantitative results. The QFD allows to implement a continuous improvement process, which will be perceptible in the short term, but above all in the medium-long term. In the specific case described in this study, an ERP software marketed by an Italian company was analyzed. The concept of quality, in this case, involved several facets: the ERP software, in fact, is considered as a combination between product and service. It is therefore necessary to satisfy its customers in a global perspective, in order to be competitive on the market. Therefore, the HoQ approach has been described, as well as the steps that make up the application of the HoQ. The results obtained were able to test the applicability of HoQ to the optimization of an existing ERP software product, capitalizing and enhancing the huge amount of data that the manufacturer usually collect to characterize their reference markets and to compete with the best international competitors. Specifically, a cluster of primary HOWs was isolated through this analysis, providing a clear and unambiguous indication (when compared with other standardization approaches) of which are the priority functionalities to be developed to make the software product more suitable for customer needs and competitive on the market. The topic addressed and the tool applied lend themselves to numerous implementation and development opportunities, in particular: In the literature there are numerous experiences that apply multi-criterial approaches as an approach of normalization of HoQ data and prioritization of technical characteristics; Improve the ability to interpret customer needs and evaluate them in a quantitative way; Allow customers to express their requests also regarding new products, which they do not know or with which they have no experience; Demand modeling to predict demand for products with certain characteristics. 


\section{Acknowledgments}

The research has been co-funded by the European Regional Development Fund (ERDF) - ROP of the Emilia-Romagna Region (IT), within the framework of the SUPER Craft project.

\section{References}

[1] Alomari, I.A.; Mohd Amir, A.; Aziz, K.A.; Md Auzair, S. (2018). Effect of Enterprise Resource Planning Systems and Forms of Management Control on Firm's Competitive Advantage. Asian J. Account. Gov., 9, 87-98, doi:10.17576/ajag-2018-09-08.

[2] Suman, S.; Pogarcic, I. (2016). Development of ERP and other large business systems in the context of new trends and technologies. Ann. DAAAM Proc. Int. DAAAM Symp., 27, 319-327, doi:10.2507/27th.daaam.proceedings.047.

[3] Kutnjak, A.; Pihir, I.; Tomicic-Pupek, K. (2020). Smart agriculture and ERP benefits in the context of digital transformation. B. Proc. 58th Int. Sci. Conf. Econ. Soc. Dev. Dev.

[4] Stojkić, Ž.; Veža, I.; Bošnjak, I. (2015). A concept of information system implementation (crmand erp) within industry 4.0. Ann. DAAAM Proc. Int. DAAAM Symp., 2015-January, 912-919, doi:10.2507/26th.daaam.proceedings.127.

[5] Xu, W.; Ou, P.; Ding, J. (2019). Study of the ERP diffusion and its impact on the firm value. Proc. - 2019 6th Int. Conf. Inf. Sci. Control Eng. ICISCE 2019, 9, 577-582, doi:10.1109/ICISCE48695.2019.00121.

[6] Van Chuong, L.; Hung, P.D.; Diep, V.T. (2019). Robotic process automation and opportunities for Vietnamese market. ACM Int. Conf. Proceeding Ser., 86-90, doi:10.1145/3348445.3348458.

[7] Laadar, H. Ben; Cherti, I.; Bahaj, M. (2019). ERP systems in SMEs between a choice \& An obligation. ACM Int. Conf. Proceeding Ser., Part F1481, 222-229, doi:10.1145/3318396.3318438.

[8] Kiran, T.S.; Reddy, A.V. (2019). Critical success factors of ERP implementation in SMEs. J. Proj. Manag., 4, 267280, doi:10.5267/j.jpm.2019.6.001.

[9] Barth, C.; Koch, S. (2019). Critical success factors in ERP upgrade projects. Ind. Manag. Data Syst., 119, 656-675, doi:10.1108/IMDS-01-2018-0016.

[10] Surasma Surung, J.; Agung Bayupati, I.P.; Agung Ayu Putri, G. (2020). The Implementation Of ERP In Supply Chain Management On Conventional Woven Fabric Business. Int. J. Inf. Eng. Electron. Bus., 12, 8-18, doi:10.5815/ijieeb.2020.03.02.

[11] Drobkova, O. (2020). Application of ERP-systems for increase of efficiency organization of high-tech production. MATEC Web Conf., 311, 02019, doi:10.1051/matecconf/202031102019.

[12] Costa, C.J.; Ferreira, E.; Bento, F.; Aparicio, M. (2016). Enterprise resource planning adoption and satisfaction determinants. Comput. Human Behav., 63, 659-671, doi:10.1016/j.chb.2016.05.090.

[13] Kryvinska, N.; Bickel, L. (2020). Scenario-Based analysis of IT enterprises servitization as a part of digital transformation of modern economy. Appl. Sci., 10, doi:10.3390/app10031076.

[14] Jahanmir, S.F.; Cavadas, J. (2018). Factors affecting late adoption of digital innovations. J. Bus. Res., 88, 337-343, doi:10.1016/j.jbusres.2018.01.058.

[15] Amirova, R.; Khoyakov, I.; Mirgalimova, R.; Sillitti, A. (2019). Software Development and Customer Satisfaction: A Systematic Literature Review.

[16] Seth, H.; Talwar, S.; Bhatia, A.; Saxena, A.; Dhir, A. (2020). Consumer resistance and inertia of retail investors: Development of the resistance adoption inertia continuance (RAIC) framework. J. Retail. Consum. Serv., 55, doi:10.1016/j.jretconser.2020.102071.

[17] Van De Poel, I. (2007). Methodological problems in QFD and directions for future development. Res. Eng. Des., 18, 21-36, doi:10.1007/s00163-007-0029-7.

[18] Durga Prasad, K.; Venkata Subbaiah, K.; Narayana Rao, K. (2010). Prioritization of Customer Needs in House of Quality Using Conjoint Analysis. Int. J., 4, 145-154.

[19] Bigorra, A.M.; Ove, I. (2016). Combining customer needs and the customer's way of using the product to set customer-focused targets in the House of Quality. Int. J. Prod. Res.

[20] Zare Mehrjerdi, Y. (2010). Quality function deployment and its extensions. Int. J. Qual. Reliab. Manag., 27, 616640, doi:10.1108/02656711011054524.

[21] Sullivan, L. (1986). Quality function deployment. Qual. Prog., 19, 39-50.

[22] Hauser, J.R.; Clausing, D. (1988). The House of Quality. Harv. Bus. Rev., doi:10.1093/nq/s12-iii.71.402b.

[23] Lager, T. (2017). A conceptual framework for platform-based design of non-assembled products. Technovation, 68, 20-34, doi:10.1016/j.technovation.2017.09.002.

[24] English, J.R. (1993). Quality Function Deployment: Integrating Customer Requirements into Product Design. J. Qual. Technol., 25, 63-64, doi:10.1080/00224065.1993.11979419.

[25] Wang, Y.; Mo, D.Y.; Tseng, M.M. (2018). Mapping customer needs to design parameters in the front end of product design by applying deep learning. CIRP Ann. 2018, 67, 145-148, doi:10.1016/j.cirp.2018.04.018.

[26] Prahalad, C.K. (2000). Ramaswamy Co-opting Customer Competence. charts Co-opting customer competence. Harv. Bus. Rev., 78, 79-9. 
[27] Agrawal, A.K.; Rahman, Z. (2015). Roles and Resource Contributions of Customers in Value Co-creation; Holy Spirit University of Kaslik, Vol. 3.

[28] Marinello, S.; Gamberini, R.; Lolli, F. (2018). The application of a Quality Function Deployment approach for the design of a B2B web platform.

[29] Talwar, S.; Talwar, M.; Kaur, P.; Dhir, A. (2020). Consumers' resistance to digital innovations: A systematic review and framework development. Australas. Mark. J., doi:10.1016/j.ausmj.2020.06.014.

[30] Heidenreich, S.; Kraemer, T. (2016). Innovations - Doomed to Fail? Investigating Strategies to Overcome Passive Innovation Resistance. J. Prod. Innov. Manag., 33, 277-297, doi:10.1111/jpim.12273.

[31] Chou, T.Y. (2020). Using FQFD and FGRA to enhance the advertising effectiveness of cross-regional e-commerce platforms. Mathematics, 8, doi:10.3390/math8040650.

[32] Barutçu, S. (2006). Quality Function Deployment in Effective Website Design: an Application in E-Store Design. Engineering, 7, 41-63.

[33] Xie, J.; Qin, Q.; Jiang, M. (2020). Multiobjective Decision-Making for Technical Characteristics Selection in a House of Quality. Math. Probl. Eng., doi:10.1155/2020/9243142.

[34] Permana, R.; Budiardjo, E.K.; Ferdinansyah, A. (2019). Assessment of software engineering process based on CMMI-QFD framework. ACM Int. Conf. Proceeding Ser., 42-46, doi:10.1145/3354142.3354150.

[35] Sun, Y.; Liu, X. (Frank) (2010). Business-oriented software process improvement based on CMMI using QFD. Inf. Softw. Technol., 52, 79-91, doi:10.1016/j.infsof.2009.08.003.

[36] Ling, N.; Fan, S.; Reng, M.; Wei, X. (2018). Research on Enterprise ERP System Functionality Design Under Mass Customization Environment. DEStech Trans. Comput. Sci. Eng., doi:10.12783/dtcse/cmee2017/20074.

[37] Yuen, K.K.F. (2014). A hybrid fuzzy quality function deployment framework using cognitive network process and aggregative grading clustering: An application to cloud software product development. Neurocomputing, 142, 95106, doi:10.1016/j.neucom.2014.03.045.

[38] Lien, C.; Chan, H.-L. (2007). A selection model for ERP system by applying fuzzy AHP approach. Int. J. Comput. internet, 58-72.

[39] Huiqun, H.; Guang, S. (2012). ERP software selection using the rough set and TPOSIS methods under fuzzy environment. Adv. Inf. Sci. Serv. Sci., 4, 111-118, doi:10.4156/AISS.vol4.issue3.15.

[40] Sofyaloglu, Ç.; Öztürk, S. (2012). A methodological approach to reduce the impacts of risk in the erp projects: Fuzzy quality function deployments. Eur. J. Sci. Res., 82, 592-606.

[41] Shih, Y.-Y. (2010). A Study of ERP Systems Selection via Fuzzy AHP Method. 2010 2nd Int. Symp. Inf. Eng. Electron. Commer.

[42] Karsak, E.E.; Özogul, C.O. (2009). An integrated decision making approach for ERP system selection. Expert Syst. Appl., 36, 660-667, doi:10.1016/j.eswa.2007.09.016.

[43] Perçin, S. (2008). Using the ANP approach in selecting and benchmarking ERP systems. Benchmarking, 15, 630649, doi:10.1108/14635770810903196.

[44] Motaki, N.; Kamach, O. (2017). ERP selection: A step-by-step application of AHP Method. Int. J. Comput. Appl., 176, 15-21, doi:10.5120/ijca2017915636.

[45] Chan, L.K.; Wu, M.L. (2002). Quality function deployment: A literature review; Vol. 143; ISBN 8522788855.

[46] Qi, J.; Hu, J.; Peng, Y.H. (2020). New design concept evaluation method involving customer preferences based on rough distance to redefined ideal solution. Comput. Ind. Eng., 147, 106677, doi:10.1016/j.cie.2020.106677.

[47] Tiwari, V.; Jain, P.K.; Tandon, P. (2016). Product design concept evaluation using rough sets and VIKOR method. Adv. Eng. Informatics, 30, 16-25, doi:10.1016/j.aei.2015.11.005.

[48] Kahraman, C.; Büyüközkan, G.; Ateş, N.Y. (2007). A two phase multi-attribute decision-making approach for new product introduction. Inf. Sci. (Ny), 177, 1567-1582, doi:10.1016/j.ins.2006.09.008.

[49] Lin, M.C.; Wang, C.C.; Chen, M.S.; Chang, C.A. (2008). Using AHP and TOPSIS approaches in customer-driven product design process. Comput. Ind., 59, 17-31, doi:10.1016/j.compind.2007.05.013.

[50] Kano, N.; Seraku, N.; Takahashi, F.; Tsjui, S. (1984). Attractive quality and must-be quality. Hinshitsu, 14, 147156.

[51] Lee, M.C.; Newcomb, J.F. (1997). Applying the Kano methodology to meet customer requirements: NASA's microgravity science program. Qual. Manag. J., 4, 95-110.

[52] Witell, L.; Löfgren, M.; Dahlgaard, J.J. (2013). Theory of attractive quality and the Kano methodology - the past, the present, and the future. Total Qual. Manag. Bus. Excell., 24, 1241-1252, doi:10.1080/14783363.2013.791117.

[53] Likert, R. (1932). A technique for the measurement of attitudes.

[54] Brehm, L.; Heinzl, A.; Markus, M.L. (2001). Tailoring ERP systems: A spectrum of choices and their implications. Proc. Hawaii Int. Conf. Syst. Sci., 00, 215, doi:10.1109/HICSS.2001.927130.

[55] Yazgan, H.R.; Boran, S.; Goztepe, K. (2009). An ERP software selection process with using artificial neural network based on analytic network process approach. Expert Syst. Appl., 36, 9214-9222, doi:10.1016/j.eswa.2008.12.022.

[56] Lyman, D. (1990). Deployment normalization.

[57] Wasserman, G.S. (1993). On How to Prioritize Design Requirements During the QFD Planning Process. IIE Trans., $25,59-65$. 